\title{
Nanocrystalline based Mitigation Technique for Very Fast Transient over Voltages in Gas Insulated Substations
}

\author{
R.Durga Rao and Dr.M.Surya Kalavathi ${ }^{\mathrm{b}}$ \\ ${ }^{a}$ Assistant Professor \& Head, Department of EEE, JNTUHCEM. \\ bProfessor (on-lien), Department of EEE, JNTUH, Vice-Chancellor, Yogi Vemana University, Kadapa
}

Article History: Received: 11 January 2021; Accepted: 27 February 2021; Published online: 5 April 2021

\begin{abstract}
: in gas insulated substations, issue of very fast transient over voltages is very familiar problem because of its effects on live ultra-high voltage equipment. During switching events of disconnectors and circuit breakers prestrikes and restrikes occur due to which voltage transients propagate through gas insulated switchgear. Reflection retraction of these transients increases voltage magnitude and generates very high frequency oscillations. Mitigation or suppression of these voltage transients is important to protect equipment and their dielectric strength and insulation. Due to very high frequency stress, they wield on the apparatus and their magnitude (up to 3.5pu), they create an important problem in the design of ultra-high voltage Gas Insulated Substations. In this paper nanocrystalline based mitigation technique for VFTOs is presented. Nanocrystalline rings can be placed around inner conductor of GIS switchgear. This method of mitigation technique is investigated with four ultra-high voltage substations simulation test setup. Simulation results are presented in MATLAB/SIMULINK
\end{abstract}

\section{Introduction}

Less space necessity, high consistency, easy maintenance are the main reasons to prefer Gas insulated substations (GIS) over Air insulated substations (AIS) in recent years. In power transmission networks, components in gas insulated substations are highly dependable and are fit for different tenders (Ezhilarasi, 2020). Sulphur hexafluoride is the gas used as insulation medium in gas insulated switchgear as space required by it is very less compared to other insulation mediums including air. Other advantages of SF6 gas are its stability to chemical effects, a high arc interruption capability and good dielectric strength. And SF6 is advisable and feasible environmentally as it is a greenhouse gas (Seeger, M., L, 2008).

As high voltage energized live components in gas insulated substation are protected by enclosure and insulated by SF6 gas external disturbances are almost negligible (Rana, 2013). Voltage and temperature characteristics of SF6 gas is significantly even. Air can endure to very high voltages for very less time. If duration of voltage increases, the withstand voltage falls off considerably. Because of flat characteristics of SF6 gas, the ratio of basic lightning impulse level is close to unity for GIS. Compared with conventional substations like air insulated, GIS based substation needless number of lighting arresters due to its firmness (Loganathan 2017).

During switching events in disconnector switches and circuit breakers of GIS, SF6 causes steep voltage rises due to prestrikes or restrikes and flashovers (Shu 2018). These voltage transients propagate through gas insulated switchgear and these electromagnetic waves reflect and refract numerous times at cut-offs due to coaxial arrangement of switchgear. VFTOs or voltage transients contain hindered impulsive form with high frequency oscillations in range of hundreds of $\mathrm{MHz}$ (Badinelli, 2010). magnitude of VFTOs may reach 3-3.5 times of rated voltage and their rise time will be in range of some nano seconds. And these transients will be rotten after some milli seconds. Distinctive GIS Modeling notion and generation of several over voltages because of switching events of disconnector switches with and without load is explained in (Nagarsheth, 2014).

High voltage live components and insulation system of these equipment will be affected much due to high stress created by VFTOs due to switching operations (Hoshina, Y2006). Radiation of these electromagnetic waves by VFTOs will also affect secondary equipment even without direct contact with live components due to ultrahigh voltage. Coordination of insulation and design of dielectric materials for gas insulated switchgear depends on ratio between voltage that can lighting impulse withstanding voltage to rated voltage (He, Jiaxi, 2014). For ultrahigh voltage substations range of VFTOs are becoming additional factor which decides insulation levels and dielectric strength of switchgear. Hence for ultra-high voltage gas insulated substations, suppression of VFTOs is becoming important factor in the view of cost and design (Rayati,2018).

Several suppression techniques are proposed and implemented by researchers. Suppression of voltage transients by inserting resistor with disconnector switch which switching operations caused VFTOs is proposed in (Ranjeeth, 2020). Damping voltage transients by ferrite rings is investigated in (Zhan, 2017). Reducing VFTOs magnitudes by reducing trapped charge during switching operation is explained in (Almenweer, 2019). Attenuation of VFTOs by RF resonator by placing it around inner conductor of GIS is proposed in (H. N. Scherer, 1969). Due to voltage transients and its electromagnetic waves resonator shift into resonance and then dissipates energy generated by VFTOs and hence mitigates them. 
In this paper VFTOs due to disconnector switches in four different ultra-high voltage rated substations due to switching process are explained and a mitigation technique of VFTOs is proposed for GIS by considering voltage magnitudes and their frequency of oscillations. Four GIS substations with different voltage levels are modelled using MATLAB/SIMULINK by considering each apparatus equivalent circuits.

\section{Nanocrystalline based Mitigation of VFTO}

Effective suppression of fast voltage transients is possible by using Nanocrystalline material rings. These rings can be placed around inner conductor of GIS switch gear. Silicon, iron and boron are the main metals used to for alloy of nanocrystalline state. Using a speedy hardening technology, these metals in liquid form can be processed into very tinny ribbons of $20 \mu \mathrm{m}$ thickness. These ribbons can be converted into rings. These tapes with amorphous microstructure will be converted into required nanocrystalline state with fine crystalline grains embedded in an amorphous residual phase using heat treatment with temperatures between 500-600oC. Diameter of these crystalline grains is in the range of $10-40 \mathrm{~nm}$. Specific properties of these materials can be adjusted by using external magnetic fields during heat treatment.

Nanocrystalline materials will be saturated magnetically by some amount of magnetic field. In gas insulated substations magnetic field strength is because of current in inner conductors is very much higher than the saturation field strength. Hence in low frequency range, there is no energy loss as the rings are magnetically saturated. If the frequency is in range of hundreds of $\mathrm{MHz}$ due to voltage transients, energy loss will occur and hence mitigation of VFTO can be achieved.

By placing nanocrystalline rings around inner conductor of gas insulated switchgear there is possibility of three types of losses may occur which leads to damping of voltage transients. By alignment change in existed magnetic domain due to external alternating magnetic field of nanocrystalline device hysteresis losses will occur. The rotating process of the magnetic domains converts the rotating energy into thermal energy. These losses are very less and inconsequential and not much contribute to damping of transients. Very fast rotating magnetic field is created by voltage transients around the inner conductor in the direction of the nanocrystalline ring winding. Interaction between these two magnetic fields generates steep field variation due to which eddy currents can be induced. Power loss due to these eddy currents suppress voltage transients and this process escalates with increase in frequency.

Transverse anisotropy behaviour of nanocrystalline rings generated micro eddy currents due to magnetization process of magnetic domains. Losses due to these micro eddy currents will contribute for suppression of VFTOs. Equivalent circuit of nanocrystalline is shown in fig 1 . Resistance, inductance, and capacitance $R_{d}, L_{d}$ and $C_{d}$ can be optimized by simulating the selected GIS substations with number of values and the values which are giving better mitigation effect of voltage transients can be chosen.

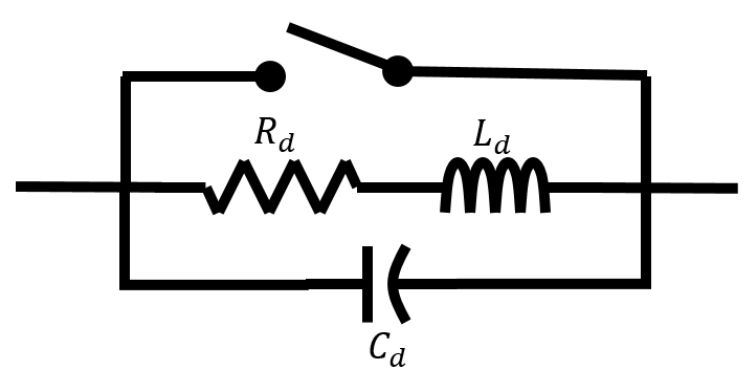

\section{GIS Substations}

Figure 1. Equivalent Circuit of nanocrystalline ring

Four ultra-high voltage rated substations are chosen to study GIS Modeling and impacts of VFTOs and their mitigation using nanocrystalline rings.

\subsection{KV Substation}

Single line diagram of $765 \mathrm{KV}$ substation is shown in fig 2 (C. Li, 2012). Normal source and back up source are connected to substation due to local requirements. 6 Disconnector switches at positions CB1-CB6 are switched to analyse VFTOs. 


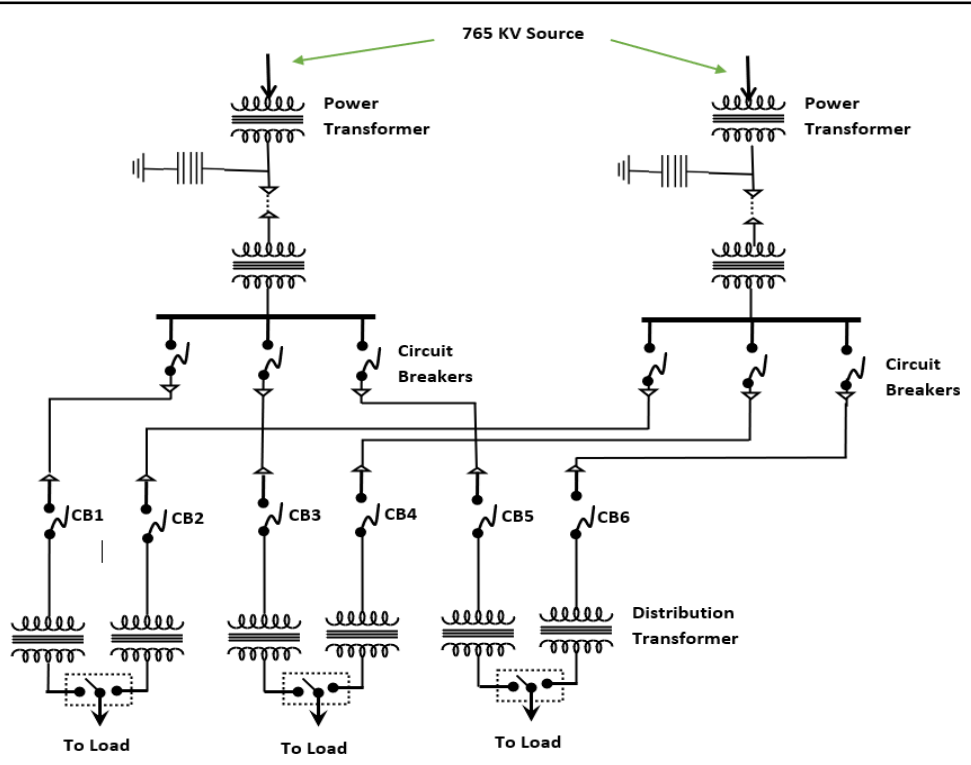

Figure 2. Single line diagram of $765 \mathrm{KV}$ substation

\section{2 $1000 \mathrm{KV}$ substation}

Single line diagram of Huainnan-Wannan 1000 KV UHV transmission system is shown in fig 3 (Nayak, R. N., 2009). Transmission line with UHV of $1000 \mathrm{KV}$ is a double circuit transmission line on same tower. Substations are located at Huainnan and wannan locations and both are based on GIS switchgear. Single line schematic diagram of Huainnan substation is shown in fig 3 (C. Li, 2012). CB1-CB6 are disconnector switches which are operated to study effect of VFTOs on system and their process of suppression by adding nanocrystalline rings. PT1-PT2 are voltage transformers and T1-T2 are auto transformers. Length of busbars are mentioned in single line diagram.

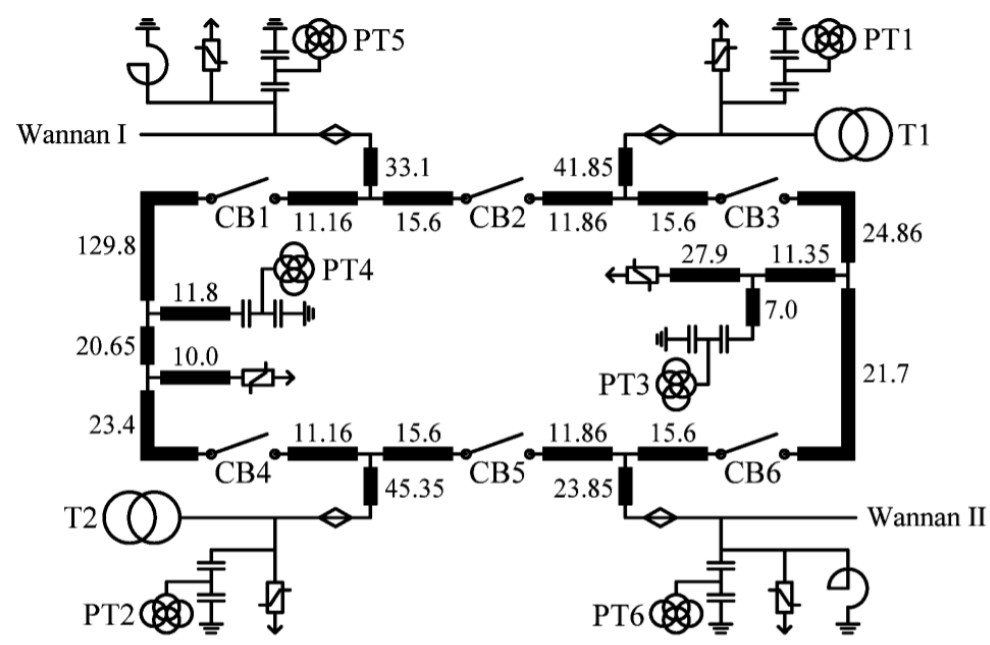

Figure 3. Single line diagram of $1000 \mathrm{KV}$ substation 


\subsection{KV and 1500 KV Substation}

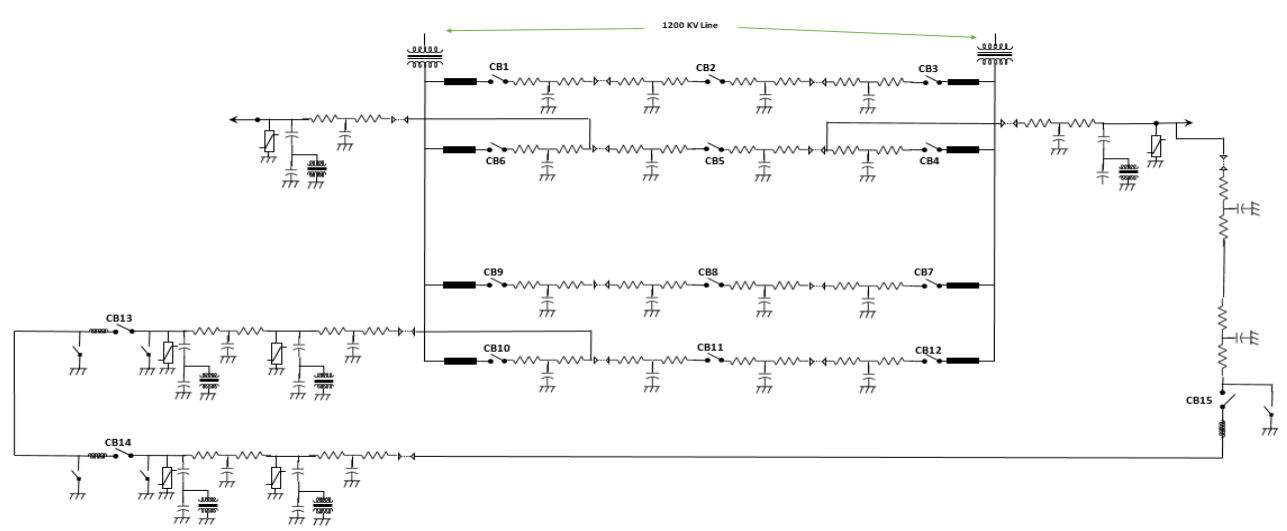

Figure 4. Single line diagram of $1200 \mathrm{KV}$ substation

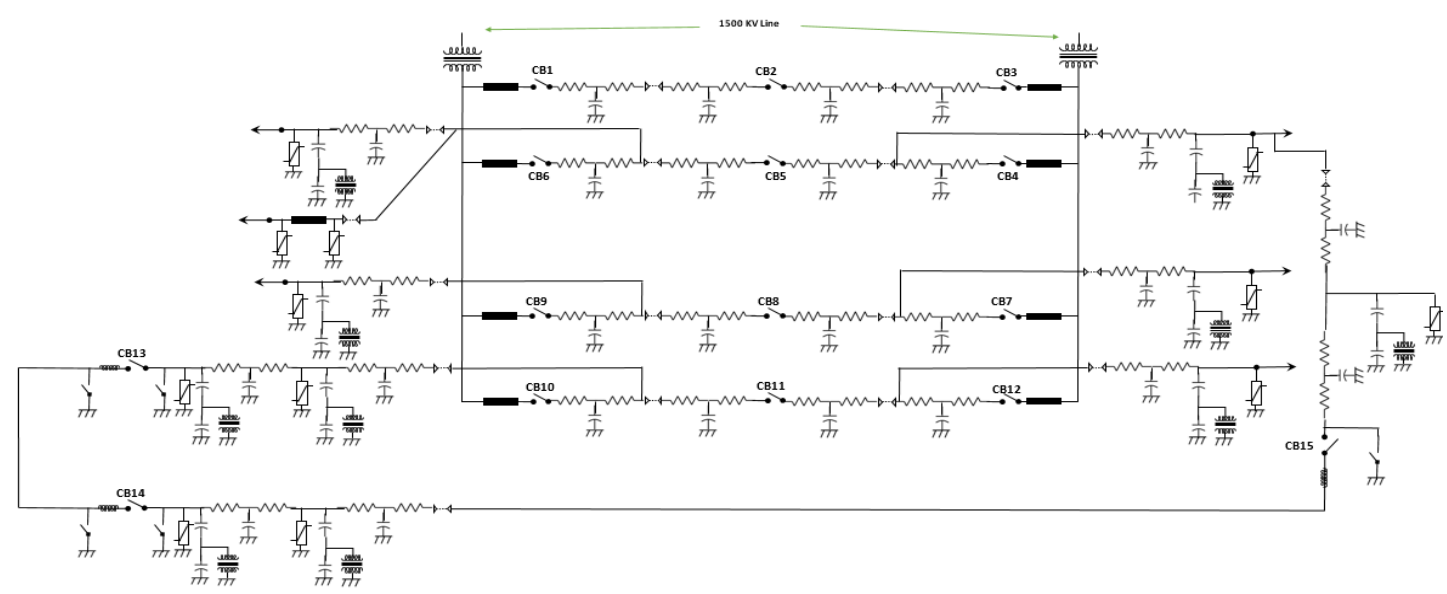

Figure 5. Single line diagram of $1500 \mathrm{KV}$ substation

A $1200 \mathrm{KV}$ test station at Bina, Madhya Pradesh India is chosen to study effect of VFTOs. This test station is modified by adding additional protecting devices like MOVs. Single line diagram of test system for $1200 \mathrm{KV}$ is shown in fig 4 and for $1500 \mathrm{KV}$ with additional protecting devices is shown in fig 5 (Loganathan 2017). Important factor to be considered for UHV substation is coordination insulation levels of various equipment in point of withstanding capability of lighting impulse and switching impulse voltage. CB1-CB15 are the disconnector switches which are operated to study VFTOs and their suppression using mitigating device.

\section{Simulation Results}

Effect of nanocrystalline rings on damping of voltage transients due to switching events is studied on four ultrahigh voltage substations. Voltage ratings of these substations are $765 \mathrm{KV}, 1000 \mathrm{KV}, 1200 \mathrm{KV}$ and $1500 \mathrm{KV}$. Each component of the substation is modelled by taking its behaviours as consideration for oscillations with high frequency and for steep rise in voltage magnitudes. Substations are modelled in MATLAB/SIMULINK using single line diagram shown in fig (Seeger, M., L, 2008; Rana, 2013; Nilges, 2018; Shu, 2018). VFTOs due to switching events of disconnector switches are recorded with ferrite rings and with Nanocrystalline rings as mitigating devices. Optimization of resistance and inductance values for ferrite rings in four UHV substations is discussed by author in his previous work. Models developed using equivalent circuits of each apparatus by taking consideration of VFTOs give accurate results of transients and magnitudes of these transients, settling times and their rise time are assessed and tabulated.

\subsection{Result analysis for $765 \mathrm{KV}$}

Disconnector switch CB1 is opened at an instant and results of VFTOs at various points of substation are presented. Fig 6 shows the results of fast voltage transients by using ferrite rings as mitigating device. $225 \mathrm{Ohms}$ and $2 \mathrm{mH}$ are the resistance and inductance values used in ferrite rings. Fig 7 present the voltage transient at same locations by replacing ferrite rings with nanocrystalline rings. Equivalent circuit of nanocrystalline ring is shown in fig 1 and resistance, inductance and capacitance in the circuit is equal to $135 \mathrm{ohms}, 0.82 \mathrm{mH}$ and $2.56 \mu \mathrm{F}$. These 
values are optimized by comparing damping effect of VFTOs by nanocrystalline rings with various values. The peak value of voltage transient using ferrite ring as mitigating device is in and around 1.6p.u. and this peak value is decreased to 1.1p.u. after replacing resistor with nanocrystalline rings due to effective dissipation of energy by eddy currents and hysteresis currents.
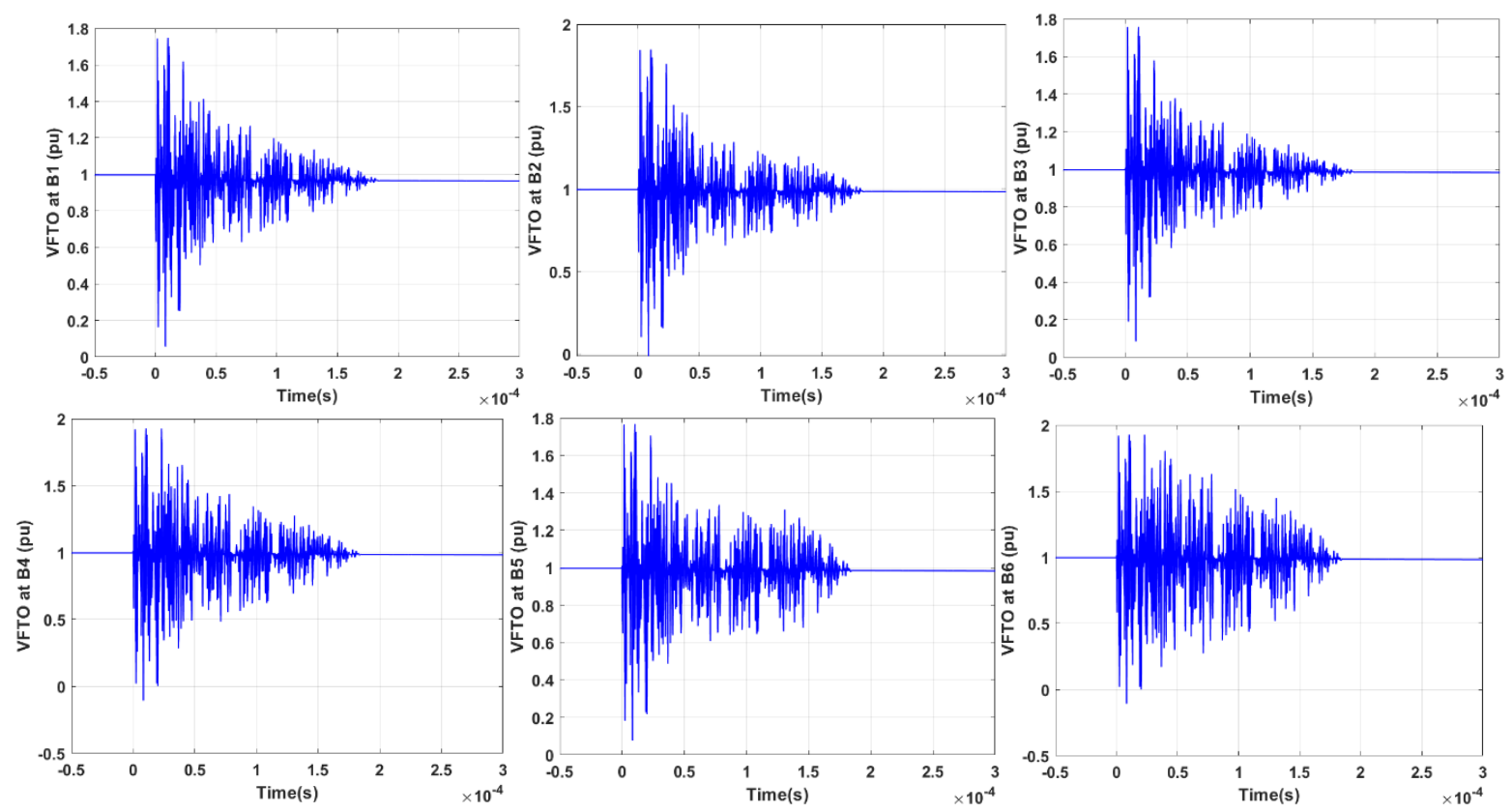

Figure 6. VFTOs at various points (B1-B6) of substation due to switching operation of CB1 disconnector switch with Ferrite rings as mitigating device
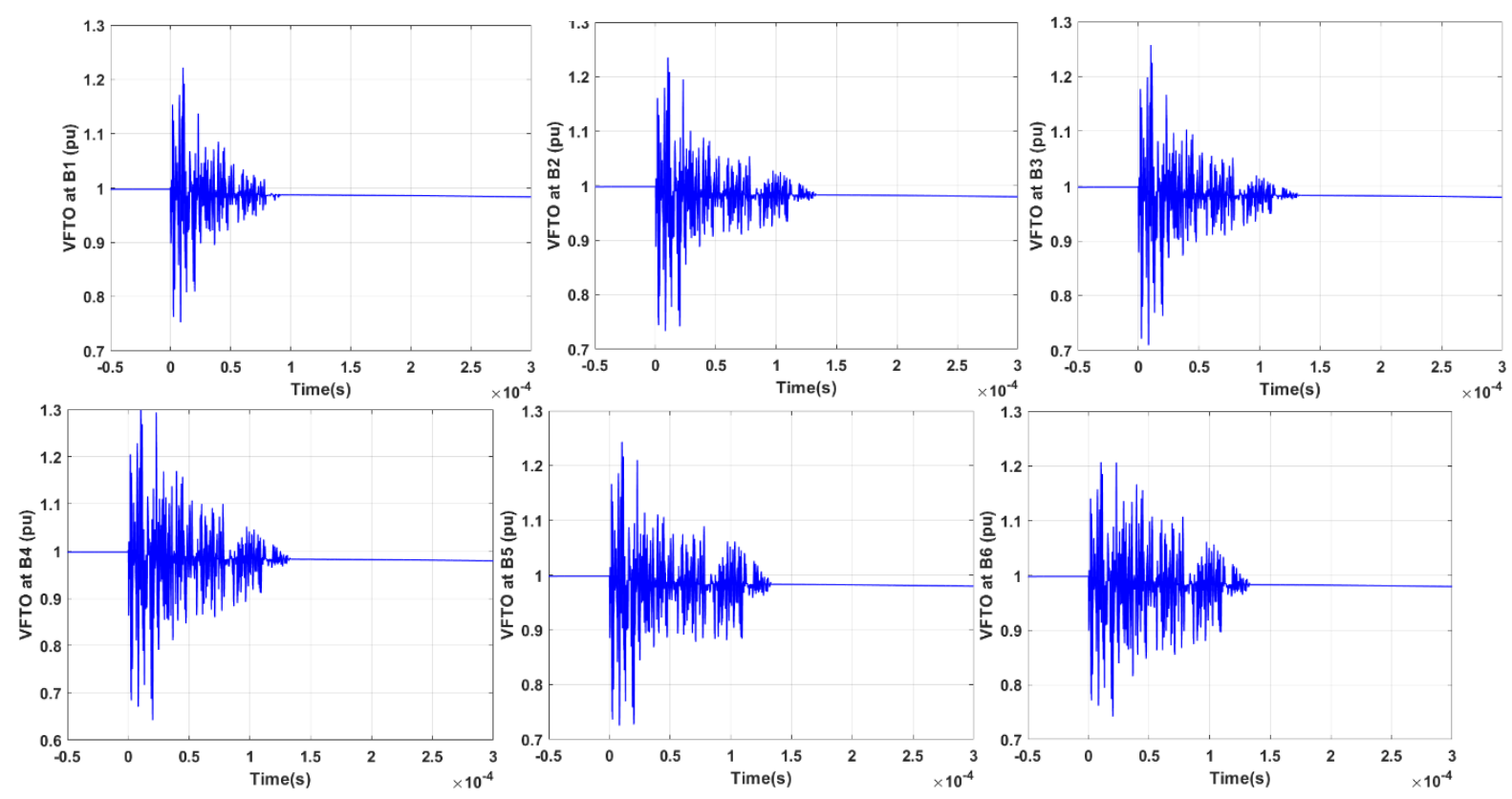

Figure 7. VFTOs at various points (B1-B6) of substation due to switching operation of CB1 disconnector switch with Nanocrystalline as mitigating device

Fig 8 presents VFTOs at locations B1-B6 with nanocrystalline rings. Magnitude of transients rise time and settling time at various locations of substation due to switching of disconnector switch (CB1) for ferrite rings and for nanocrystalline rings as mitigating devices is shown in table 1. Voltage transients' peak value is reduced by $30 \%$ and settling time is reduced by $40-50 \mu$ seconds by replacing ferrite rings with nanocrystalline rings. 
Table 1. VFTOs magnitude, settling time and rise time for $765 \mathrm{KV}$ substation with ferrite ring and nanocrystalline as mitigating device

\begin{tabular}{|c|c|c|c|c|c|c|}
\hline $\begin{array}{r}\text { Measur } \\
\text { ed location }\end{array}$ & \multicolumn{3}{|c|}{ With Ferrite Rings as mitigating device } & \multicolumn{3}{c|}{ With Nanocrystalline as mitigating device } \\
\hline & $\begin{array}{c}\text { Magnitu } \\
\text { de (p.u.) }\end{array}$ & $\begin{array}{c}\text { Rise } \\
\text { time }(\mu \text { sec })\end{array}$ & $\begin{array}{c}\text { Settling } \\
\text { time }(\mu \text { sec })\end{array}$ & $\begin{array}{c}\text { Magnitud } \\
\text { e (p.u. })\end{array}$ & $\begin{array}{c}\text { Rise } \\
\text { time }(\mu \text { sec })\end{array}$ & $\begin{array}{c}\text { Settling } \\
\text { time }(\mu \text { sec })\end{array}$ \\
\hline CB1 & 1.69 & 1.15 & 162.5 & 1.22 & 0.982 & 83.3 \\
\hline CB2 & 1.68 & 1.141 & 163.85 & 1.23 & 0.993 & 121.32 \\
\hline CB3 & 1.71 & 1.142 & 169.21 & 1.24 & 0.992 & 120.6 \\
\hline CB4 & 1.82 & 1.175 & 162.85 & 1.29 & 1.015 & 119.85 \\
\hline CB5 & 1.78 & 1.149 & 160.78 & 1.22 & 0.998 & 121.7 \\
\hline CB6 & 1.83 & 1115 & 160.5 & 1.2 & 0.993 & 120.85 \\
\hline
\end{tabular}
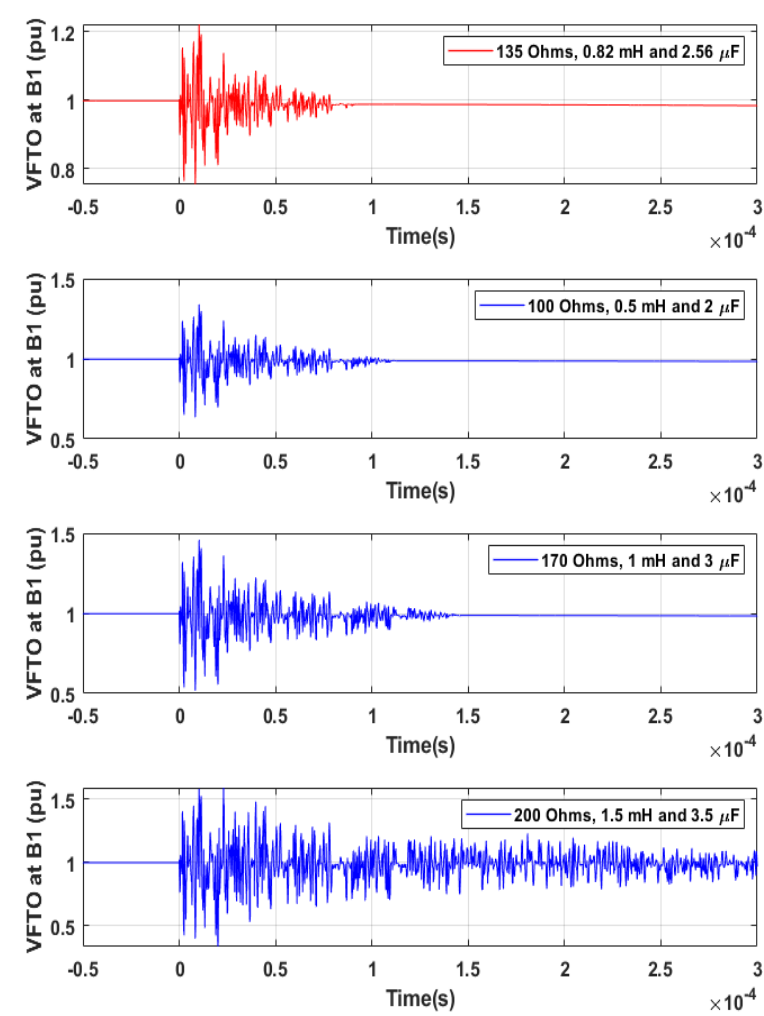
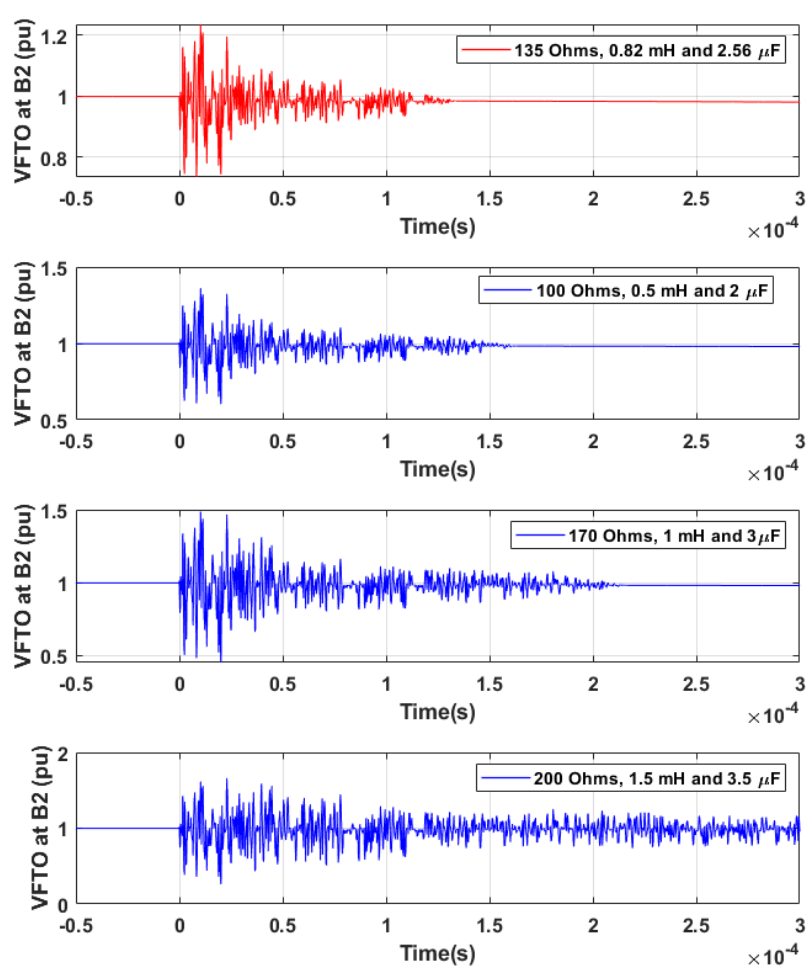

Figure 8. VFTOs at B1 and B2 locations of substation for 4 different values of resistor, inductor, and capacitor in Nanocrystalline

\subsection{Result analysis for $1000 \mathrm{KV}$ substation}

For $1000 \mathrm{KV}$ substation, $115 \mathrm{ohms}$ and $3.35 \mathrm{mH}$ are the values chosen for resistance and inductance in ferrite rings and results of VFTOs are presented in fig 9. In this case peak value of voltage transients are reduced to 1.6pu. As nanocrystalline device $109 \mathrm{ohms}, 3.98 \mathrm{mH}$ and $4.02 \mu \mathrm{F}$ are chosen for resistance, inductance, and capacitance respectively for mitigating voltage transients and results are presented in fig 10. In this case peak value of voltage transients are reduced to 1.1pu. Effect of VFTO at B1 and B2 position for 4 different values of nanocrystalline rings is shown in fig11. Magnitude of VFTOs, rise time and settling time after adding ferrite rings and nanocrystalline device as mitigating devices is tabulated in table. 


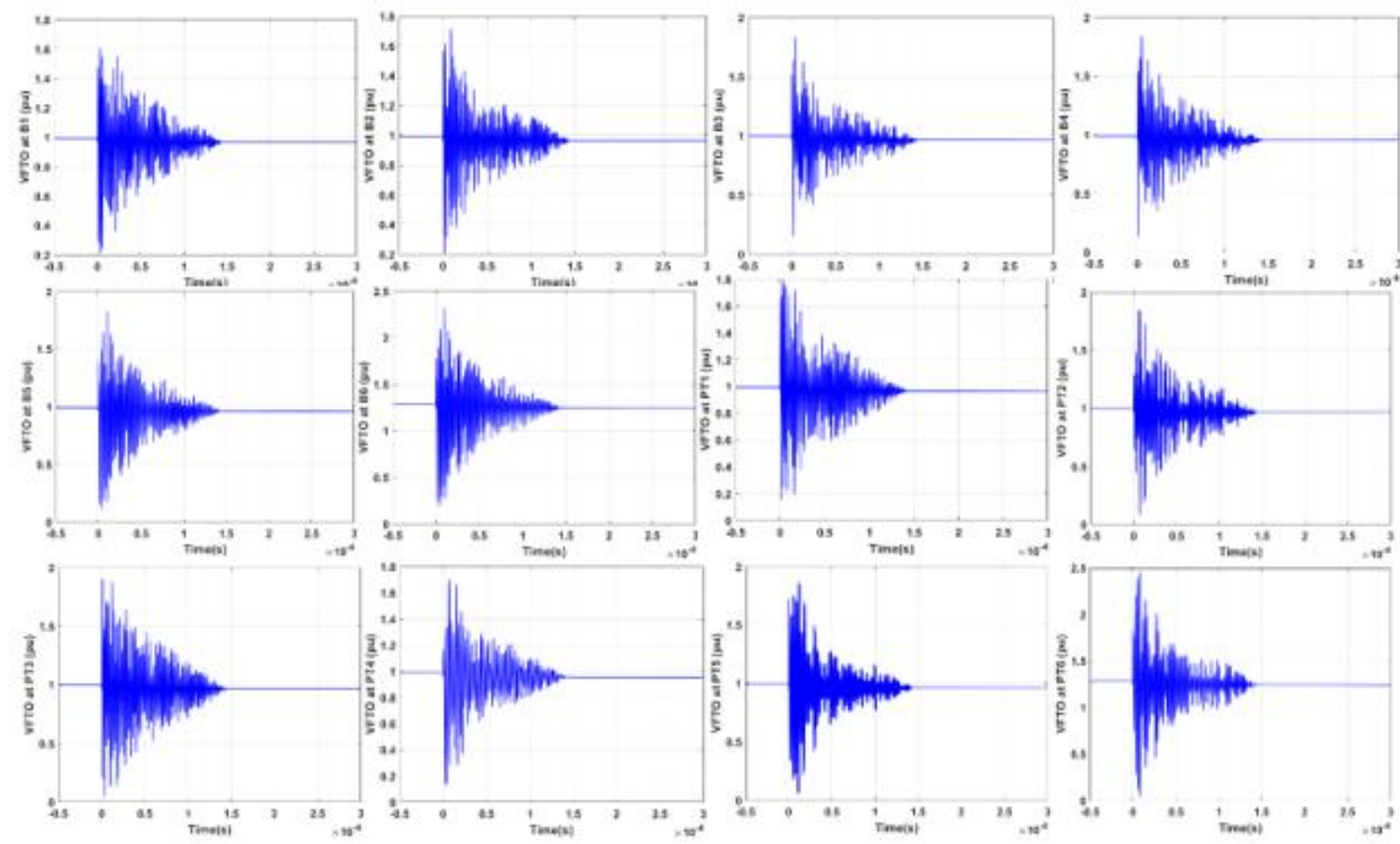

Figure 9. VFTOs at disconnector switches (CB1-CB6) and at potential transformers (PT1-PT6) of 1000 KV substation due to switching operation of CB1 disconnector switch with Ferrite Rings as mitigating device

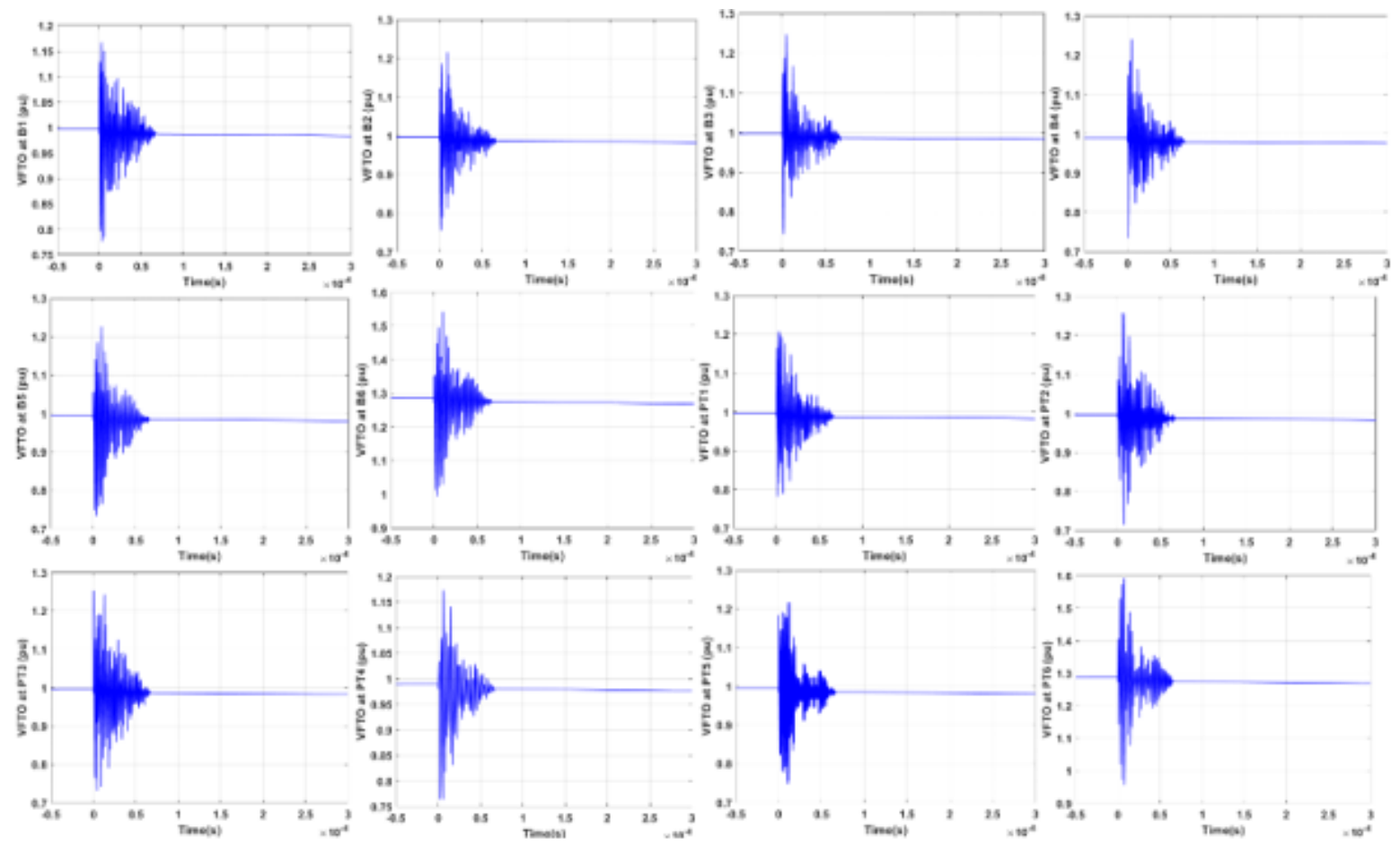

Figure 10. VFTOs at disconnector switches (CB1-CB6) and at potential transformers (PT1-PT6) of 1000 $\mathrm{KV}$ substation due to switching operation of CB1 disconnector switch with Nanocrystalline as mitigating device 
Table 2. VFTOs magnitude, settling time and rise time for $1000 \mathrm{KV}$ substation with ferrite ring and nanocrystalline as mitigating device

\begin{tabular}{|c|c|c|c|c|c|c|}
\hline $\begin{array}{r}\text { Measur } \\
\text { ed location }\end{array}$ & \multicolumn{2}{|c|}{$\begin{array}{c}\text { With additional Ferrite Rings as mitigating } \\
\text { device }\end{array}$} & \multicolumn{3}{|c|}{$\begin{array}{c}\text { With additional Nanocrystalline as mitigating } \\
\text { device }\end{array}$} \\
\hline & $\begin{array}{c}\text { Magnitu } \\
\text { de (p.u.) }\end{array}$ & $\begin{array}{c}\text { Rise } \\
\text { time }(\mu \text { sec })\end{array}$ & $\begin{array}{c}\text { Settling } \\
\text { time }(\mu \text { sec })\end{array}$ & $\begin{array}{c}\text { Magnitud } \\
\text { e (p.u.) }\end{array}$ & $\begin{array}{c}\text { Rise } \\
\text { time }(\mu \text { sec })\end{array}$ & $\begin{array}{c}\text { Settling } \\
\text { time }(\mu \text { sec })\end{array}$ \\
\hline CB1 & 1.6 & 1.139 & 142.8 & 1.151 & 1.032 & 60.7 \\
\hline CB2 & 1.7 & 1.126 & 141.36 & 1.22 & 0.975 & 55.3 \\
\hline CB3 & 1.62 & 1.13 & 140.22 & 1.23 & 0.983 & 54.27 \\
\hline PT1 & 1.79 & 1.125 & 139.56 & 1.2 & 0.975 & 54.14 \\
\hline PT2 & 1.75 & 1.139 & 140.05 & 1.22 & 0.988 & 55.3 \\
\hline PT3 & 1.73 & 1.134 & 140.4 & 1.23 & 0.996 & 54.2 \\
\hline
\end{tabular}
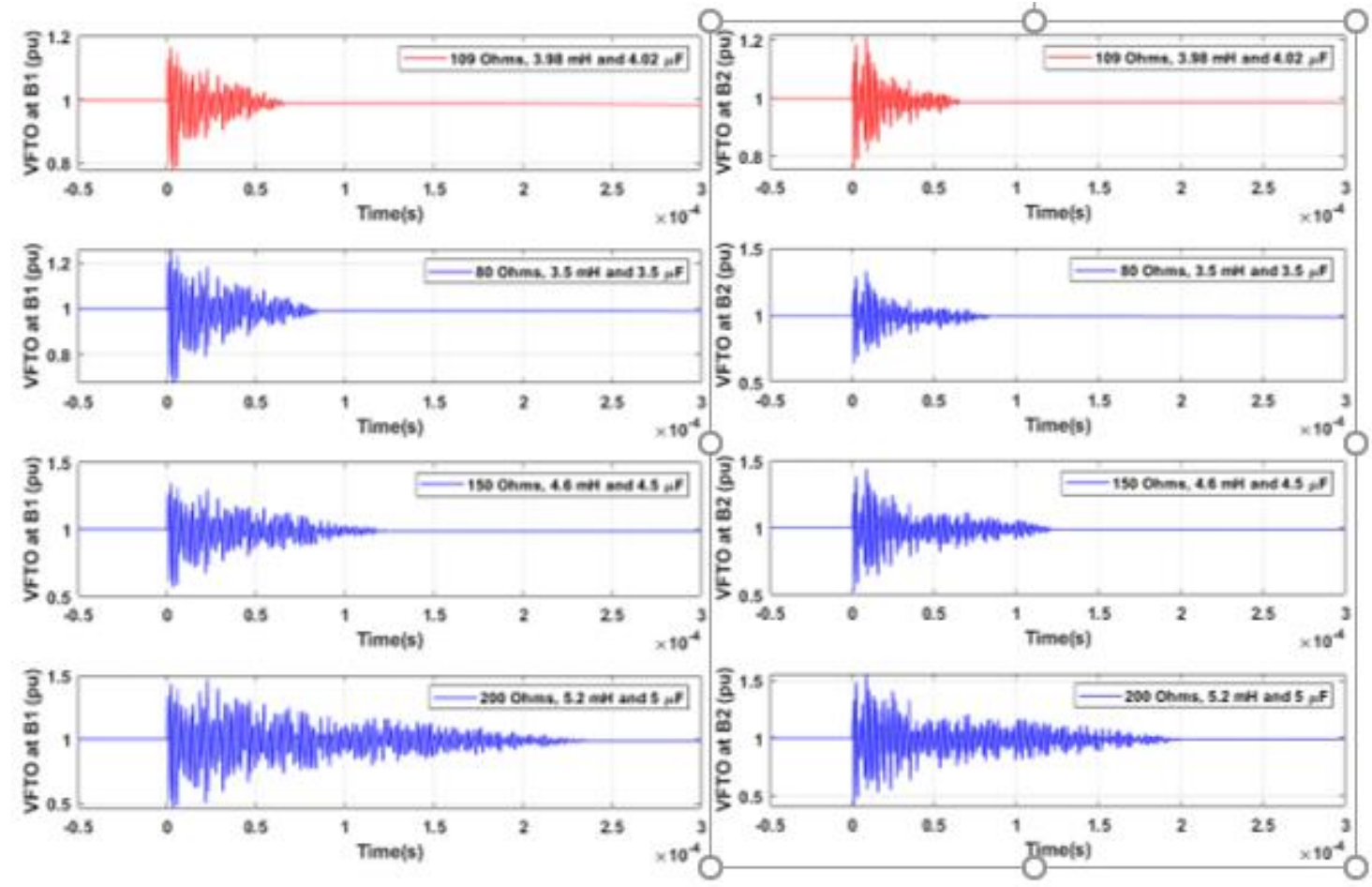

Figure 11. VFTOs at B1 and B2 locations of substation for 4 different values of resistance, inductance, and capacitance in Nanocrystalline device

\subsection{Result analysis for $1200 \mathrm{KV}$ substation}

VFTOs at various points of $1200 \mathrm{KV}$ substation shown in fig 12 and fig 13 due to switching of CB1 disconnector switch with ferrite rings and with nanocrystalline ring as mitigating devices are presented. Voltage transients at locations at disconnector switches (CB1-CB15) and at potential transformers (PT1-PT11) are shown in fig 12 with ferrite rings and in fig 13 with nanocrystalline device. $276 \mathrm{ohms}$ and $2.33 \mathrm{mH}$ are the values chosen for resistance and inductance in ferrite rings and $183 \mathrm{ohms}, 3.26 \mathrm{mH}$ and $2.855 \mu \mathrm{F}$ are chosen for resistance, inductance and capacitance in nanocrystalline rings' magnitudes and their respective settling and rise times are tabulated for CB1-CB3 and PT1-PT3 with ferrite rings and with nanocrystalline ring. VFTOs for four different nanocrystalline rings at B1 and B2 location are shown in fig 14 to check efficacy of proposed values of resistance, capacitance, and inductance. After replacing ferrite rings with nanocrystalline device as mitigating device in disconnector switch reduces voltage transient magnitudes by $20 \%$ and reduces settling time by $40-50 \mu$ seconds. 


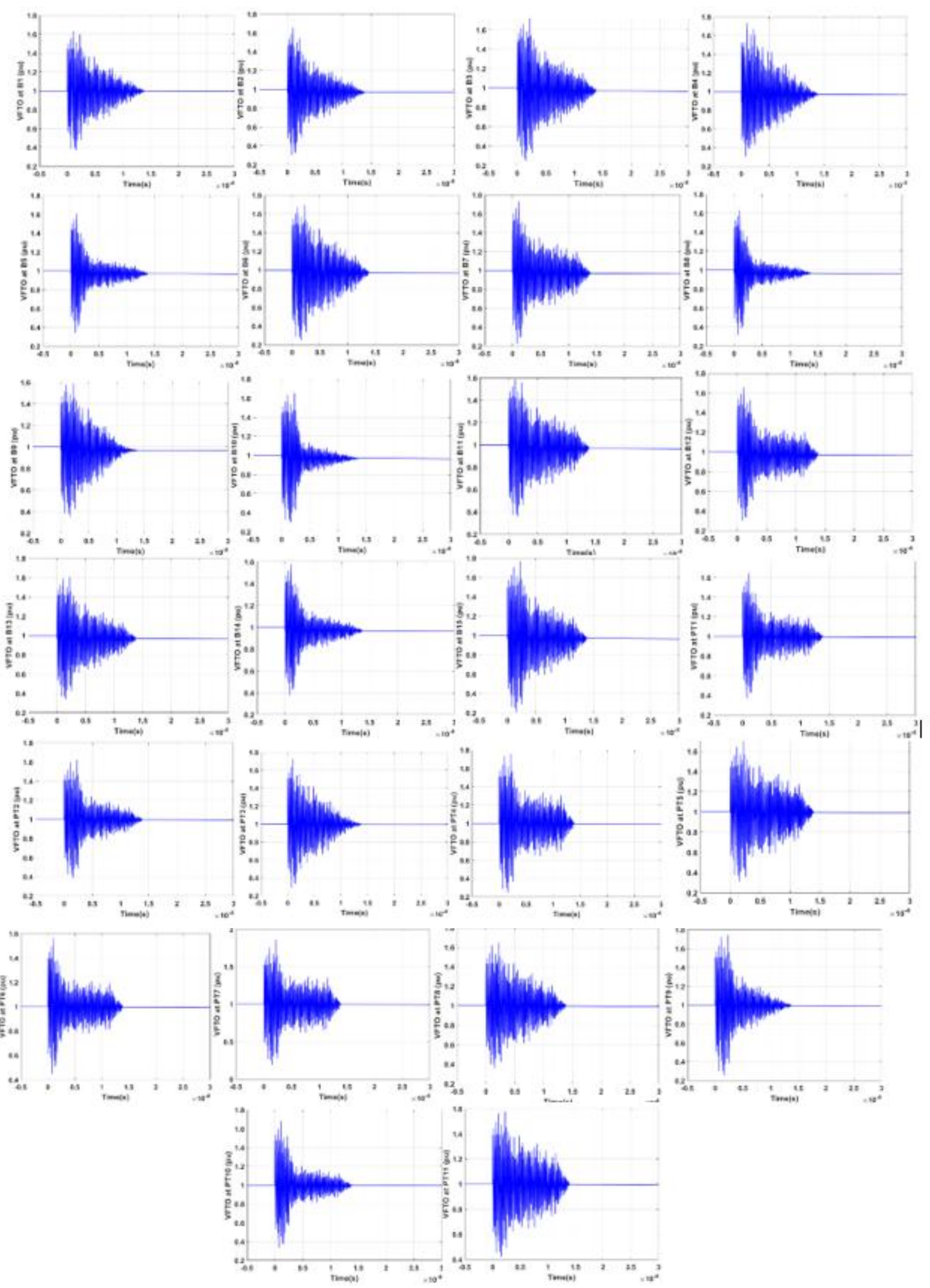

Figure 12. VFTOs at disconnector switches (CB1-CB15) and at potential transformers (PT1-PT11) of 1200 KV substation due to switching operation of $\mathrm{CB} 1$ disconnector switch with Ferrite Rings as mitigating device 

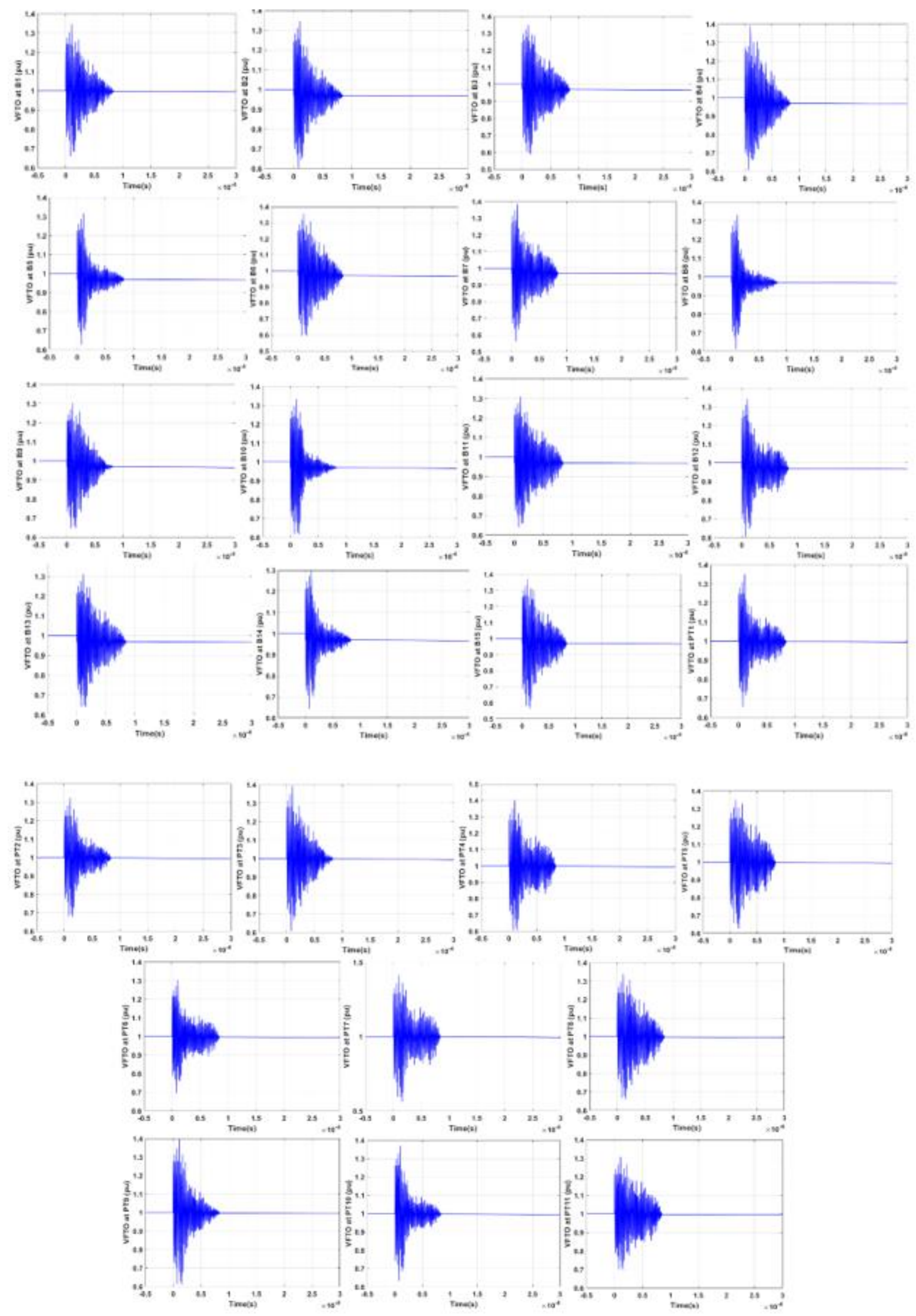

Figure 13. VFTOs at disconnector switches (CB1-CB15) and at potential transformers (PT1-PT11) of 1200 $\mathrm{KV}$ substation due to switching operation of CB1 disconnector switch with Nanocrystalline as mitigating device 
Table 3. VFTOs magnitude, settling time and rise time for $1200 \mathrm{KV}$ substation with ferrite ring and nanocrystalline as mitigating device

\begin{tabular}{|c|c|c|c|c|c|c|}
\hline $\begin{array}{r}\text { Measur } \\
\text { ed location }\end{array}$ & \multicolumn{2}{|c|}{$\begin{array}{c}\text { With additional Ferrite Rings as mitigating } \\
\text { device }\end{array}$} & \multicolumn{3}{|c|}{$\begin{array}{c}\text { With additional Nanocrystalline as mitigating } \\
\text { device }\end{array}$} \\
\hline & $\begin{array}{c}\text { Magnitu } \\
\text { de (p.u.) }\end{array}$ & $\begin{array}{c}\text { Rise } \\
\text { time }(\mu \text { sec })\end{array}$ & $\begin{array}{c}\text { Settling } \\
\text { time }(\mu \text { sec })\end{array}$ & $\begin{array}{c}\text { Magnitud } \\
\text { e (p.u. })\end{array}$ & $\begin{array}{c}\text { Rise } \\
\text { time }(\mu \text { sec })\end{array}$ & $\begin{array}{c}\text { Settling } \\
\text { time }(\mu \text { sec })\end{array}$ \\
\hline CB1 & 1.59 & 1.11 & 132.5 & 1.3 & 0.895 & 72.35 \\
\hline CB2 & 1.45 & 1.06 & 130.5 & 1.31 & 0.756 & 69.2 \\
\hline CB3 & 1.62 & 1.10 & 131.62 & 1.3 & 0.797 & 69.75 \\
\hline PT1 & 1.48 & 1.105 & 131.1 & 1.31 & 0.812 & 70.12 \\
\hline PT2 & 1.5 & 1.11 & 130.85 & 1.31 & 0.811 & 70.05 \\
\hline PT3 & 1.41 & 1.116 & 129.56 & 1.3 & 0.795 & 69.11 \\
\hline
\end{tabular}
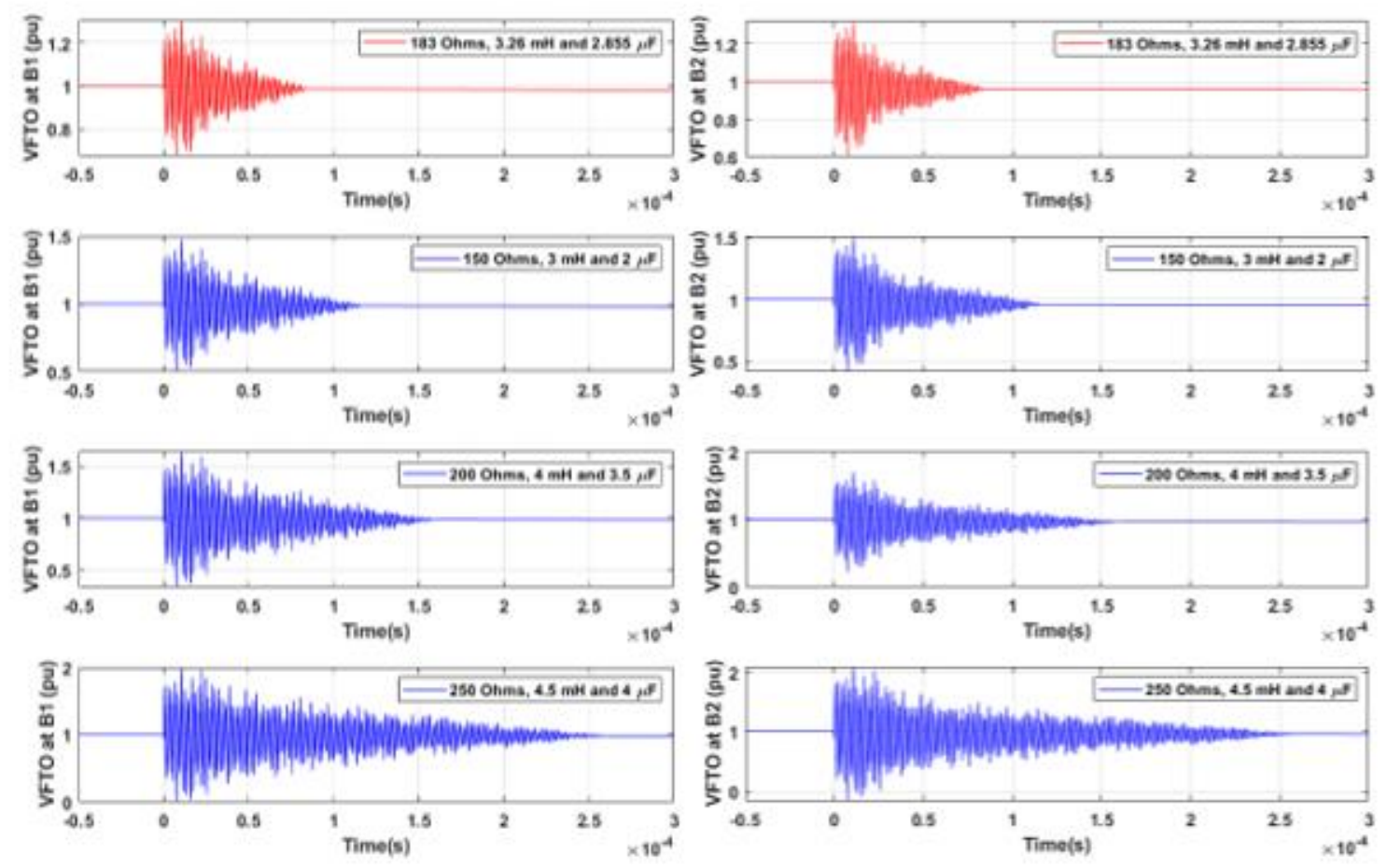

Figure 14. VFTOs at B1 and B2 locations of substation for 4 different values of resistance, inductance and capacitance in Nanocrystalline device

\subsection{Result analysis for $1500 \mathrm{KV}$ substation}

$1500 \mathrm{KV}$ GIS substation and its components are modelled by considering their behaviour to high voltage oscillations and simulated by applying switching event on disconnector switches to check effect of VFTOs on various points of substation. Single line diagram of $1500 \mathrm{KV}$ substation is shown in fig 5 is modelled and simulated with Ferrite Rings and with Nanocrystalline as mitigating devices. After simulating and examining generated VFTOS magnitude and their decay time for different values of nanocrystalline components resistance, inductance and capacitance are optimized as $85 \Omega, 5.89 \mathrm{mH}$ and $4.96 \mu \mathrm{F}$, respectively. Settling and rise times of transients and their peak values are tabulated for CB1-CB3 and PT1-PT3 with Ferrite Rings and with Nanocrystalline in table. Fig 17 present voltage transients due to four different parameters of nanocrystalline device at B1 and B2 location to check efficacy of proposed values of resistance, inductance, and capacitance. After replacing Ferrite Rings with nanocrystalline as mitigating device in disconnector switch reduces voltage transient magnitudes by $30 \%$ and reduces settling time by $40-50 \mu$ seconds. Peak magnitude of VFTOs is changing in between 1.31-1.38p.u. with Ferrite Rings and 1.1-1.165p.u. with Nanocrystalline device. 

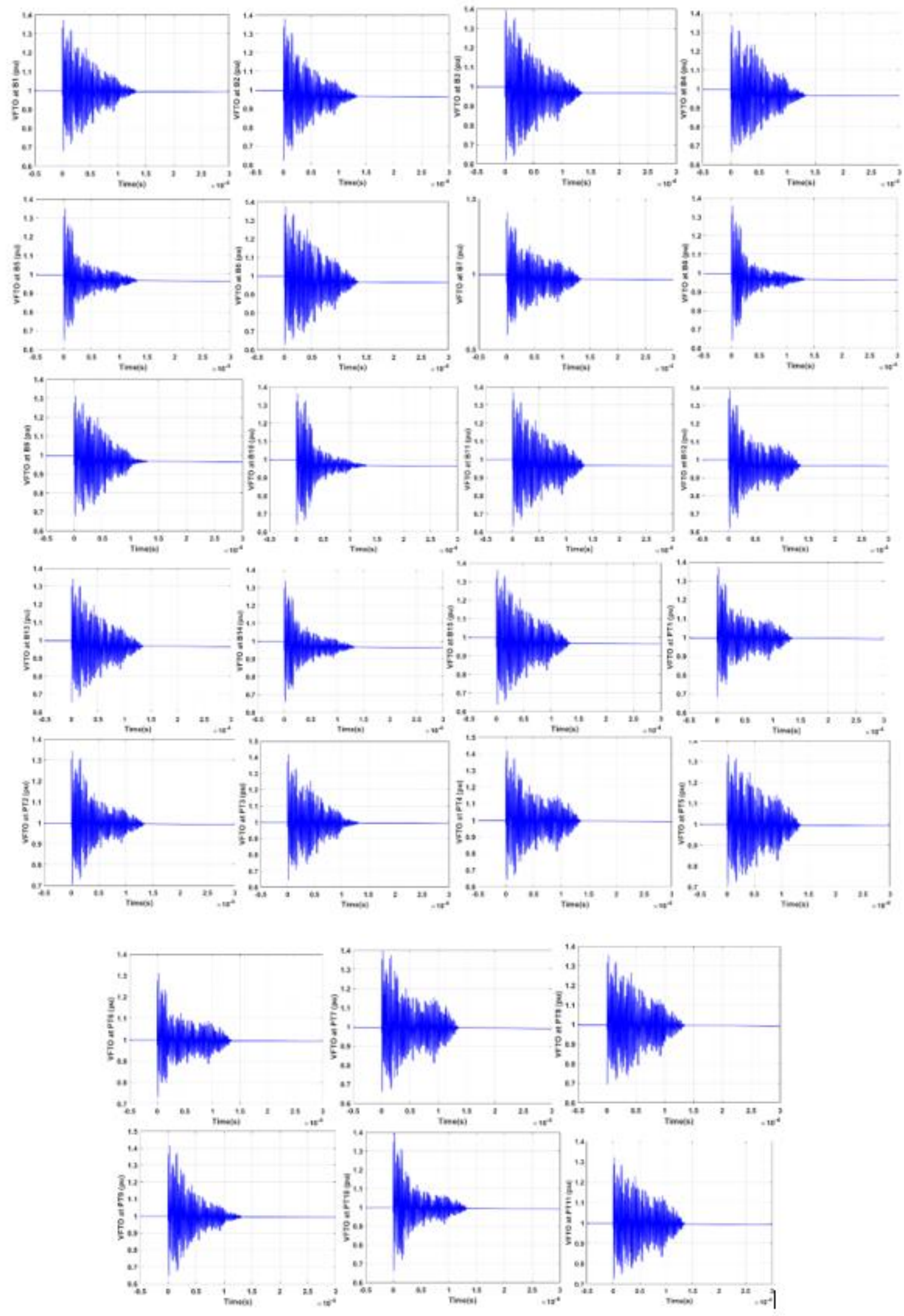

Figure 15. VFTOs at point of connection of switches (CB1-CB15) and at potential transformers (PT1PT11) of $1500 \mathrm{KV}$ substation due to switching operation of CB1 disconnector switch with Ferrite Rings as mitigating device 

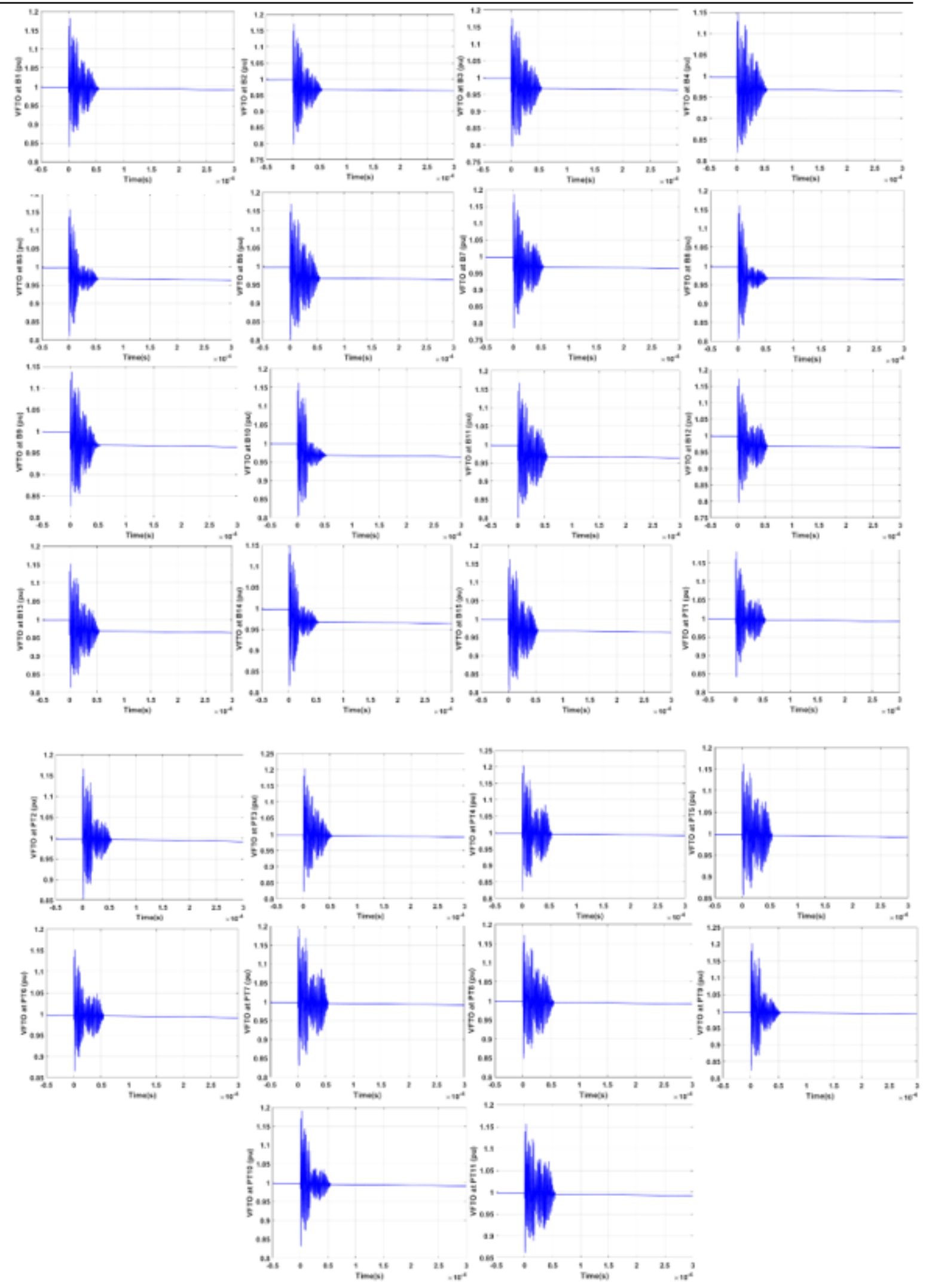

Figure 16. VFTOs at point of connection of switches (CB1-CB15) and at potential transformers (PT1-PT11) of $1500 \mathrm{KV}$ substation due to switching operation of CB1 disconnector switch with Nanocrystalline as mitigating device

Table 4. VFTOs magnitude, settling time and rise time for $1500 \mathrm{KV}$ substation with ferrite ring and nanocrystalline as mitigating device 


\begin{tabular}{|c|c|c|c|c|c|c|}
\hline $\begin{array}{r}\text { Measur } \\
\text { ed location }\end{array}$ & \multicolumn{3}{|c|}{ With Ferrite Rings as mitigating device } & \multicolumn{3}{|c|}{ With Nanocrystalline as mitigating device } \\
\hline & $\begin{array}{c}\text { Magnitu } \\
\text { de (p.u.) }\end{array}$ & $\begin{array}{c}\text { Rise } \\
\text { time }(\mu \text { sec })\end{array}$ & $\begin{array}{c}\text { Settling } \\
\text { time }(\mu \text { sec })\end{array}$ & $\begin{array}{c}\text { Magnitud } \\
\text { e (p.u. })\end{array}$ & $\begin{array}{c}\text { Rise } \\
\text { time }(\mu \text { sec })\end{array}$ & $\begin{array}{c}\text { Settling } \\
\text { time }(\mu \text { sec })\end{array}$ \\
\hline CB1 & 1.35 & 1.10 & 129.5 & 1.16 & 0.725 & 51.2 \\
\hline CB2 & 1.38 & 1.06 & 128.3 & 1.162 & 0.68 & 50.75 \\
\hline CB3 & 1.39 & 1.11 & 128.3 & 1.16 & 0.75 & 51.4 \\
\hline PT1 & 1.31 & 1.12 & 128.61 & 1.16 & 0.792 & 50.11 \\
\hline PT2 & 1.33 & 1.11 & 129.2 & 1.161 & 0.695 & 50.85 \\
\hline PT3 & 1.35 & 1.095 & 129.56 & 1.161 & 0.612 & 51.3 \\
\hline
\end{tabular}
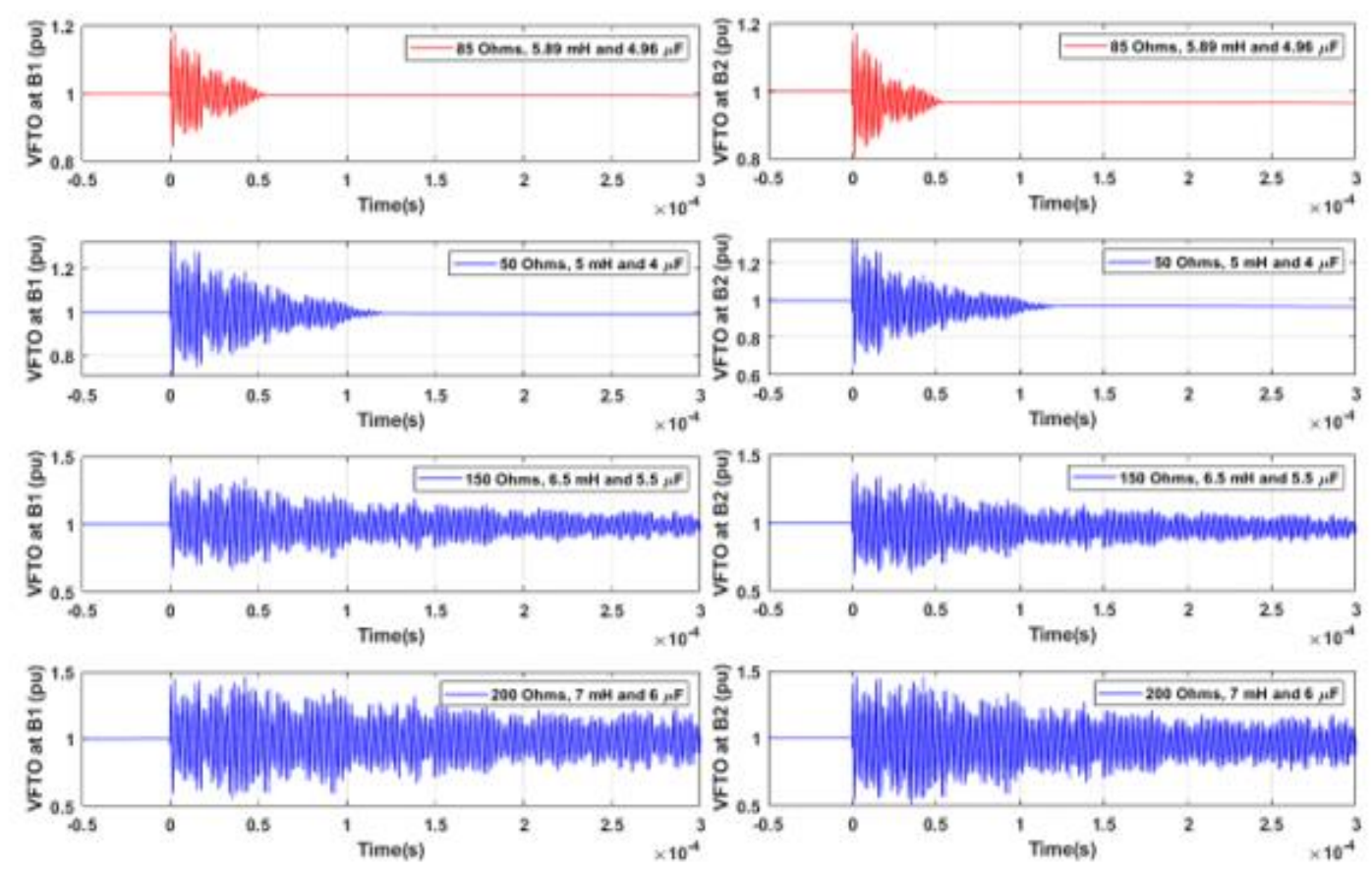

Figure 17. VFTOs at B1 and B2 locations of substation for 4 different values of resistance, inductance and capacitance in Nanocrystalline device

\section{Conclusion}

A new approach for suppression of very fast transient over voltages is presented in this paper. Response of nanocrystalline materials to other magnetic fields and their specific properties can be adjusted by heat treatment. By some amount of magnetic field nanocrystalline materials will be saturated. In gas insulated substations magnetic field strength is because of current in inner conductors is very much higher than the saturation field strength. Hence in low frequency range, there is no energy loss as the rings are magnetically saturated. If the frequency is in range of hundreds of $\mathrm{MHz}$ due to voltage transients, energy loss will occur and hence mitigation of VFTO can be achieved. These nanocrystalline rings can be placed around the inner conductor of gas insulated switchgear. By increasing number of rings damping effect on voltage transients can be increased. Very low diameter and high permeability of the rings increase effect of damping. Nanocrystalline rings are modelled as parallel connected resistance, inductance, and capacitance with disconnector switch. These values are optimized by simulating the selected GIS substations with number of values and the values which are giving better mitigation effect of voltage transients are chosen. Four ultra-high voltage substations with rating of $765 \mathrm{KV}, 1000 \mathrm{KV}$, $1200 \mathrm{KV}$ and $1500 \mathrm{KV}$ substations are chosen to check feasibility of proposed suppression technique. Optimized values of resistance, inductance and capacitance are compared with other values to check efficacy of proposed values. Magnitude of VFTOs and settling times at different locations of substations are tabulated. From results It was clear that the first amplitude of the VFTO was mitigated from $30-40 \%$ and settling times are reduced by 30 $50 \mu$ seconds. 


\section{References}

1. Almenweer, Reem A., YixinSu, and Xixiu Wu, (2019). Comparison between suppressing approaches of very fast transient over voltages in gas insulated substation. Journal of Physics: Conference Series. 1303(1). IOP Publishing.

2. Badinelli, Ralph D., Virgilio Centeno, and BoonyaritIntiyot, (2010). GIS-based simulation studies for power systems education. Operation and Control of Electric Energy Processing Systems, 119.

3. C. Li, J. He, J. Hu, R. Zeng and J. Yuan, (2012). Switching Transient of 1000-kV UHV System Considering Detailed Substation Structure, in IEEE Transactions on Power Delivery, 27(1):112-122, doi: 10.1109/TPWRD.2011.2172696.

4. Ezhilarasi, T. P., Dilip, G., Latchoumi, T. P., \& Balamurugan, K. (2020). UIP-A Smart Web Application to Manage Network Environments. In Proceedings of the Third International Conference on Computational Intelligence and Informatics (pp. 97-108). Springer, Singapore.

5. He, Jiaxi, et al, (2014). Experimental research and simulation on VFTO mitigation by ferrite rings in UHV GIS. IEEE Transactions on Power Delivery 30(2): 940-948.

6. He, Jiaxi, et al. (2015). Design optimization of ferrite rings for VFTO mitigation. IEEE Transactions on Power Delivery 32(3): 1181-1186.

7. H. N. Scherer, C. A. Schwalbe, R. H. Meyer and J. A. Dibella, (1969). 765-kV Station Design, in IEEE Transactions on Power Apparatus and Systems, PAS-88 (9):1372-1376, doi: 10.1109/TPAS.1969.292528.

8. Hoshina, Y., et al, (2006). Lightning impulse breakdown characteristics of SF6 alternative gases for gasinsulated switchgear. IEEE Proceedings-Science, Measurement and Technology 153(1): 1-6.

9. Loganathan, J., Janakiraman, S., \& Latchoumi, T. P. (2017). A Novel Architecture for Next Generation Cellular Network Using Opportunistic Spectrum Access Scheme. Journal of Advanced Research in Dynamical and Control Systems,(12), 1388-1400.

10. Loganathan, J., Janakiraman, S., Latchoumi, T. P., \& Shanthoshini, B. (2017). Dynamic Virtual Server for Optimized Web Service Interaction. International Journal of Pure and Applied Mathematics, 117(19), 371-377.

11. Loganathan, J., Latchoumi, T. P., Janakiraman, S., \& parthiban, L. (2016, August). A novel multi-criteria channel decision in co-operative cognitive radio network using E-TOPSIS. In Proceedings of the International Conference on Informatics and Analytics (pp. 1-6).

12. Nayak, R. N., et al. (2009). $1200 \mathrm{kV}$ transmission system and status of development of substation equipment/transmission line material in India. Water and Energy International 66(4): 70-77.

13. Pohlink, K., et al. (2006). New aspects of reliability in gas insulated substations. IEEE Power Engineering Society General Meeting. IEEE.

14. Rana, Pavan, and Ashesh Mehta, (2013). GIS technology-new generation products \& integrated GIS application. Journal International Association on Electricity Generation, Transmission and Distribution 26(1): 11-25.

15. Ranjeeth, S., Latchoumi, T. P., \& Paul, P. V. (2020). Role of gender on academic performance based on different parameters: Data from secondary school education. Data in brief, 29, 105257.

16. Rayati, Mohammad, and Ali Mohammad Ranjbar, (2018). Optimum damping resistance of potential transformers for mitigating ferro-resonance in gas insulated substations. International Journal of Electrical Power \& Energy Systems 103: 553-561.

17. Seeger, M., L. Niemeyer, and M. Bujotzek, (2008). Partial discharges and breakdown at protrusions in uniform background fields in SF6." Journal of Physics D: Applied Physics 41(18):185204.

18. Shu, Yinbiao, and Weijiang Chen, (2018). Research and application of UHV power transmission in China. High voltage 3(1): 1-13.

19. Zhan, Huamao, et al. (2017). Influence of switching properties of the disconnector on very fast transient overvoltage. IEEE Electrical Insulation Conference (EIC). IEEE. 